УДК 621.391

DOI: https://doi.org/10.26642/ten-2019-2(84)-100-108

І.А. Пількевич, д.т.н., проф.

Державний університет «Житомирська політехніка»

О.С. Бойченко, к.т.н.

І.В. Гуменюк, к.т.н., ст. викл.

Житомирський військовий інститут імені С.П. Корольова

\title{
Метод децентралізованого управління мережевими ресурсами інформаційно-комунікаційних мереж
}

\begin{abstract}
У роботі наведено теоретичний опис запропонованого методу синтезу бездротових інформаційно-комунікаційних мереж передачі даних шляхом кластеризації вузлів та виділенням основних елементів функціонування: контролерів кластерів, вузлів-илюзів та кластеризованих вузлів з метою забезпечення зменшення службового трафіку при вирішенні завдань покращення якості обслуговування та функиіонування мобільних мереж. Для синтезу мережі на основі проведеного аналізу обрано алгоритм k-середніх, виходячи з його простоти реалізачії та заздалегідь відомої кількості мережевих кластерів, на яку необхідно розподілити (кластеризувати) вузли. Основна метрика, щуо використовується при проведенні кластеризачіі та розподілення бездротової інформаційно-комунікаційної мережі на кластерні зони обрано метричну (евклідову) відстань між мережевими вузлами. При ініціалізації синтезованої мережі обсяг службового трафіка збільшується (на 10-12\%) за рахунок виокремлення службовоі інформаціі для визначення основних структурних елементів функціонування мережі (контролерів кластерів, вузлів-илюзів, кластеризованих вузлів тощчо). Показано, щчо застосування методу надає значне зменшення службового трафіка порівняно з відомими методами управління мережевими ресурсами під час власне самої передачі інформації, причому приріст переваги залежить від кількості кластерних зон, на яку розподіляється інформаційнокомунікаційна мережа. Запропонований метод синтезу дочільно застосовувати для забезпечення якісного та надійного функиіонування бездротових інформаційно-комунікаційних мереж, у тому числі й глобальних/локальних мобільних, в умовах обмеження мережевих ресурсів та відсутньої або зруйнованої мережевої інфраструктури.

Ключові слова: службовий трафік; інформаційно-комунікаційна мережа; динамічна маршрутизація; децентралізоване управління; кластер; продуктивність мережі.
\end{abstract}

Постановка проблеми у загальному вигляді. Сучасні бездротові інформаційно-комунікаційні мережі являють собою складні ієрархічні багаторівневі системи, ефективність яких залежить від багатьох параметрів: показники якості обслуговування, надійності, продуктивності тощо. У той самий час значення цих показників може значно змінюватися залежно від поточної завантаженості мережі.

Недоліком таких мереж $є$ використання проміжних вузлів для передачі даних, що може викликати затримку при передачі інформації, у наслідок чого погіршується (знижується) якість трафіка в режимі реального часу. У зв'язку з цим в бездротових мережах використовуються спеціальні протоколи, які дозволяють кожній точці доступу створювати таблиці абонентів мережі 3 контролем стану транспортного каналу і підтримкою динамічної маршрутизації трафіка по оптимальному маршруту між сусідніми точками. За умови відмови будь-якої з них відбувається перенаправлення трафіка іншим маршрутом, що гарантує доставку інформаційних пакетів кінцевому адресату, але при цьому вибір маршруту безпосередньо впливає на оперативність їх доставки [1, с. 157].

У даний час з розвитком телекомунікаційних технологій, підвищенням швидкості та обсягів передачі інформації актуальним стає питання управління мережами передачі даних, що зводиться до процесів моніторингу та контролю стану вузлів, їх взаємодій та каналів зв'язку.

Пропускна здатність бездротової мережі обмежується максимальною ефективною використовуваного логічного каналу. Частина цієї пропускної здатності використовується для передачі даних, решта - для неклієнтського трафіка, що містить в собі службовий трафік та значну кількість спеціальних пакетів. Складність структури бездротової мережі призводить до зростання потоків службової інформації і зменшення корисного трафіка. Відповідно, завдання зменшення службового трафіка є актуальним та становить науковий та практичний інтерес.

Виходячи з даних передумов, сформульовано мету цієї статті, яка полягає у розробці і застосуванні методів децентралізованого управління мережевими ресурсами, а саме, зменшення службового трафіка при вирішенні завдань покращення якості обслуговування мережі.

(C) І.А. Пількевич, О.С. Бойченко, І.В. Гуменюк, 2019 
Аналіз останніх досліджень та публікацій. Питання зменшення службового трафіка $\epsilon$ досить актуальними. Так у роботі [2, с. 3250] розглядається задача зменшення службового трафіка комп'ютерної мережі, обговорюються питання пошуку ефективних рішень забезпечення допустимого навантаження для робочих станцій, запропоновано оцінку навантаження службовим трафіком з урахуванням достатньої забезпеченості інформативності процесу моніторингу. Впровадження запропонованої моделі та алгоритму [3, с. 67] в практичні розробки здатне зменшити локальні перевантаження в окремих вузлах, адаптувати мережу до трафіка, характерного для мультисервісних додатків. Запропонований метод [4, с. 102] дозволяє зменшити інтенсивність потоку службового трафіка на критичній ділянці мультисервісної мережі та збільшити розмір мережевого ресурсу. При прогнозуванні інтенсивності трафіка критичної ділянки враховується фрактальний характер його інформаційної та службової компонент. Запропоновано [5, с. 100] загальні принципи динамічної маршрутизації цифрових потоків, які зменшують затримки часу на маршрутизацію і службовий трафік у каналах зв'язку. Досліджується проблема [6, с. 550] зниження обсягу розсилки службової інформації при використанні протоколу детермінованого доступу, описаного в стандарті IEEE 802.11 s мереж Wi-Fi Mesh. Протокол детермінованого доступу дозволяє станціям мережі завчасно резервувати інтервали часу для одержання в них безконкурентного доступу до каналу, побудовано аналітичну й імітаційну моделі роботи алгоритму, що дозволяють оцінити обсяг переданого службового трафіка.

Постановка завдання. Для бездротової інформаційно-комунікаційної мережі необхідно: провести кластеризацію вузлів 3 відомою кількістю $-N$; визначити їх доступність та сформувати таблиці маршрутизації; визначити елементи функціонування мережі. Для оцінювання ефективності передачі даних потрібно розраховувати безрозмірний коефіцієнт $K_{\kappa л}$.

Викладення основного матеріалу дослідження. При розробці протоколів маршрутизації часто виникає проблема визначення оптимального маршруту доставки інформації в мережі зі складною топологією. При низьких навантаженнях ефективними $є$ протоколи 3 алгоритмами одношляхової маршрутизації. Але збільшення мультимедійного навантаження призводить до нерівномірного розподілу трафіка бездротової мережі: навантаження на одні канали зв'язку зростає, на інші - зменшується. Рішенням проблеми на рівні мережевих протоколів $є$ впровадження таких алгоритмів управління (балансування) трафіком, при яких раціонально використовуватиметься як можна більша кількість каналів зв'язку.

Протоколи маршрутизації бездротових мереж мобільних абонентів, що самоорганізовуються, розділяють на групи: протоколи 3 проактивною маршрутизацією, протоколи 3 реактивною маршрутизацією, гібридні [7, с. 200].

Проактивні протоколи допускають наявність у кожному вузлі таблиць маршрутизації, де вказані маршрути до будь-якого іншого вузла мережі. Вузли мережі здійснюють періодичний обмін повідомленнями для підтримки цілісності інформації про структуру мережі. Використання проактивних протоколів призводить до швидкого зростання завантаження мережі і сукупних витрат енергоресурсів кожного вузла при збільшенні мобільності і кількості вузлів мережі.

У протоколах реактивної групи вузол шукає шлях до пункту призначення тільки при виникненні необхідності. Для встановлення зв'язку він може використовувати існуючий маршрут або створювати новий, маючи інформацію про доступні канали.

Гібридні протоколи поєднують в собі підходи проактивних і реактивних протоколів на різних рівнях ієрархії. Недоліком гібридних протоколів $є$ відносна складність реалізації і зниження ефективності маршрутизації, пов'язані 3 необхідністю розподілення мережі на кластери. Структурний підхід (кластерний аналіз і візуалізація даних) припускає виділення компактних груп об'єктів, віддалених один від одного, відшукує «природнє» розподілення сукупності на області скупчень об’єктів.

Алгоритми кластеризації можуть використовуватися для поліпшення таких показників продуктивності мережі, як затримка маршрутизації, сукупні витрати енергії, пропускна здатність i масштабованість [8, с. 115].

Ефективність протоколу кластеризації розрізняється відповідно до різних цілей проектів, залежно від програм, для яких вони розроблені. У конкретному випадку, для багатошляхової маршрутизації, заснованої на кластеризації, існує ряд властивостей, які потрібно розглянути при виборі алгоритму кластеризації (стійкість, час збіжності тощо) [9, с. 138]. При застосуванні кластеризації, як і інших методів статистичного дослідження, об'єкти мають володіти однорідністю і повнотою. Подібність об'єктів визначається на основі метрики, обраної згідно з критерієм кластеризації. Щоб визначити однотипність об'єктів необхідно скласти вектор характеристик для кожного об'єкта - як правило, це набір числових значень, однак існують також алгоритми, що працюють з якісними характеристиками. Вибір метрики істотно впливає на якість кластеризації.

При використанні чисельних методів кластерного аналізу визначення подібності проводиться за допомогою евклідової відстані [10] 


$$
D\left(x_{i}, x_{j}\right)=\sqrt{\sum_{k=1}^{n}\left(x_{i k}-x_{j k}\right)^{2}},
$$

що є варіантом метрики Мінського при $p=2$ :

$$
D\left(x_{i}, x_{j}\right)=\left(\sum_{k=1}^{n}\left|x_{i k}-x_{j k}\right|^{p}\right)^{\frac{1}{p}} .
$$

Вибір метрики істотно впливає на якість кластеризації. У цій роботі використовується один із відомих методів кластеризації - $k$-середніх, який $є$ своєрідним модифікованим симбіозом алгоритмів FOREL i EM [11, с. 40]. Цей метод заснований на розподіленні множини об'єктів (вузли мережі) $V$ на $k$ кластерів, які локально мінімізовані по відстані між інформаційною точкою і центрами кластерів. Цільова функція алгоритму представлена формулою:

$$
J=\sum_{h=1}^{k} \sum_{v_{i} \in V_{h}}\left\|v_{i}-\mu_{h}\right\|^{2},
$$

де $\mu_{h}$ - значення центрів кластера.

Цільова функція є локально мінімізованою для кожного кластера (кожна точка з набору об'єктів знаходитися на мінімальній відстані від центра кластера, до якого вона належить). Вибір відповідного кластера для заданої точки в процесі роботи алгоритму обумовлений:

$$
\left\|v_{i}-\mu_{h}\right\|^{2}=\min \left\{\left\|v_{i}-\mu_{h}\right\|^{2}\right\}_{h=1}^{k} .
$$

Цей метод найбільш повно відповідає вимогам простоти застосування та зручності інтерпретації результатів кластеризації.

Розглянемо два випадки структури мережі.

1. Мережа складається $3 N$ вузлів, які містять таблицю маршрутизації, що складається зі списку суміжних (сусідніх) вузлів. Така таблиця заповнюється при отриманні HELLO-повідомлень. Вузол, що отримав повідомлення від попереднього, в таблиці маршрутизації формує новий запис про доступність, при цьому здійснюється обчислення відстані маршруту. За лавинним алгоритмом [12, с. 33] формується зв'язок зі всіма сусідніми вузлами, при цьому оцінюється різниця відстаней між ними, що дає можливість утворити вектор маршруту передачі даних. В основі лавинної маршрутизації лежить ефект розмноження пакетів, при якому вузол, отримавши пакет, генерує додаткові, ідентичні 3 ним пакети і передає їх в усі напрямки, крім того, яким надійшов пакет. Таким чином, копії пакета лавиноподібно поширюються по мережі. Перевага методу полягає у забезпеченні мінімальної затримки поширення пакетів, оскільки використовуються всі шляхи через мережу, у тому числі найкоротший. Недоліком $є$ суттєве зменшення пропускної здатності мережі.

2. Оскільки важливим завданням управління мереж є зменшення об'єму службового трафіка та, відповідно, збільшення об'єму корисної інформації, для мереж необхідно використовувати ієрархічне управління, розподіливши мережу на окремі зони (кластери) з виокремленням контролерів кластера, вузлів-шлюзів і внутрішніх вузлів кластера.

Множина $N$ вузлів мережі передачі даних розподіляється на $k$ кластери з використанням відомих алгоритмів кластеризації. При цьому кожен кластер містить однакову кількість внутрішніх вузлів, визначається опорна мережа контролерів кластерів та вузли-шлюзи, які формують віртуальну магістраль [13] усієї мережі. Ця магістраль використовується як для передачі маршрутної інформації, так і для користувацького трафіка.

При формуванні таблиць маршрутизації варто враховувати те, що кожен вузол кластера володіє інформацією про те, як він зв'язаний із сусідніми вузлами та із контролером опорної мережі відповідного кластера. Контролери кластерів у своїй маршрутній таблиці містять інформацію про зв'язність із вузлами-шлюзами на фізичному рівні та 3 контролерами на логічному. Вузли-шлюзи різних кластерів мають прямий зв'язок один з одним та містять інформацію про маршрут до відповідних контролерів кластерів. Сусідство вузлів визначається геометричним положенням області кластера. Подібне з'єднання дозволяє одержати виграш у таких випадках:

- економія сукупних витрат енергії при надсиланні широкомовного пакета всім контролерам кластера;

- зміна маршруту тільки за потреби (вузол кластера змінив своє положення, відбулося перепризначення його до іншого кластера);

- зниження об’єму службової інформації шляхом скорочення кількості вузлів, якими необхідно іiі передавати.

Розглянемо детальніше процедуру формування основних елементів мережі. 
Етап ініціалізації мережі.

1. Етап визначення контролерів кластерів. Територіально-розподілені на непересічні кластери абоненти за відомими методами на максимальному енергетичному рівні (усі вузли знаходяться в зоні дії хоча б одного доступного вузла) розсилають HELLO-повідомлення з метою визначення доступності усіх вузлів з урахуванням метрики кожного кластера. За отриманими відповідями кожний вузол визначає максимально можливу кількість вузлів, яка може бути підключена до нього та формує таблицю зв'язності (табл. 1). Вузли кожен-кожному, в тому числі через транзитні (НОР-повідомлення), відправляють Cluster-повідомлення та визначається вузол як потенційно можливий контролер кластера із максимальним ступенем зв'язаності (кількістю підключених до нього вузлів). Ця властивість притаманна алгоритмy Highest Connectivity (найвища зв'язаність), в якому переслідується мета скорочення кількості кластерів у мережі.

Таблиия 1

Cluster-повідомлення

\begin{tabular}{|c|c|c|c|}
\hline $\begin{array}{c}\text { Ідентифікатор } \\
\text { вузла }\end{array}$ & Доступні вузли & Ступінь зв'язаності & Час актуальності \\
\hline IP & $<$ HopSet $>$ & <HopCount $>$ & $<\mathrm{tm}>$ \\
\hline$\ldots$ & $\ldots$ & $\ldots$ & $\ldots$ \\
\hline
\end{tabular}

Контролер кластера в свою чергу розсилає повідомлення кожному вузлу кластера, формуючи нову таблицю маршрутизації (табл. 2). При цьому використовується нова метрика мережі - вартість маршруту від кожного вузла до контролера. Маршрут визначається одним із методів дискретної математики

Таблиия 2

Таблиия маршрутизаџї контролера кластера мережі

\begin{tabular}{|c|c|c|c|c|}
\hline $\begin{array}{c}\text { Ідентифікатор } \\
\text { контролера } \\
\text { кластера }\end{array}$ & $\begin{array}{c}\text { Ідентифікатор } \\
\text { вузла }\end{array}$ & Маршрут & $\begin{array}{c}\text { Вартість } \\
\text { маршруту }\end{array}$ & $\begin{array}{c}\text { Час } \\
\text { актуальності }\end{array}$ \\
\hline cluster & IP & <route> & <cost_route> & $<$ tm> \\
\hline$\ldots$ & $\ldots$ & $\ldots$ & $\ldots$ & $\ldots$ \\
\hline
\end{tabular}

На логічному рівні зв'язку кожен контролер має іншу таблицю маршрутизації (табл. 3), яка відображає віртуальний рівень опорної мережі контролерів кластерів.

Таблиия маршрутизаиї контролера віртуального рівня мережі

Таблиия 3

\begin{tabular}{|c|c|c|c|}
\hline $\begin{array}{c}\text { Ідентифікатор } \\
\text { контролера кластера }\end{array}$ & $\begin{array}{c}\text { Ідентифікатор контролера } \\
\text { суміжного кластера }\end{array}$ & $\begin{array}{c}\text { Вартість } \\
\text { маршруту }\end{array}$ & $\begin{array}{c}\text { Час } \\
\text { актуальності }\end{array}$ \\
\hline cluster & hop_cluster & <cost_route> & $<$ tm> \\
\hline$\ldots$ & $\ldots$ & $\ldots$ & $\ldots$ \\
\hline
\end{tabular}

2. Етап визначення вузлів-илюзів. Вузли різних кластерів з урахуванням однакової метрики мережі розсилають один одному, у тому числі і через транзитні вузли, повідомлення 3 метою визначення відстаней між ними. Вузли різних кластерів формують тимчасову таблицю маршрутизації, в якій міститься інформація про відповідні відстані. Вузли різних кластерів з мінімальними значеннями відстаней визначаються як потенційно можливі вузли-шлюзи. Ці вузли формують власні таблиці маршрутизації до потенційних контролерів (табл. 4) та шлюзів інших кластерів (табл. 5).

Таблиия 4

Таблиия маршрутизащії илюзів кластера мережі

\begin{tabular}{|c|c|c|c|c|}
\hline $\begin{array}{c}\text { Iдентифікатор } \\
\text { шлюза } \\
\text { кластера }\end{array}$ & $\begin{array}{c}\text { Ідентифікатор } \\
\text { контролера } \\
\text { кластера }\end{array}$ & $\begin{array}{c}\text { Маршрут до } \\
\text { контролера }\end{array}$ & $\begin{array}{c}\text { Вартість } \\
\text { маршруту }\end{array}$ & $\begin{array}{c}\text { Час } \\
\text { актуальності }\end{array}$ \\
\hline bridge & cluster & < cluster_route> & <cost_route> & $<$ tm> \\
\hline$\ldots$ & $\ldots$ & $\ldots$ & $\ldots$ \\
\hline
\end{tabular}


Таблиия марирутизачії илюзів кластера мережі

\begin{tabular}{|c|c|c|c|c|}
\hline $\begin{array}{c}\text { Ідентифікатор } \\
\text { шлюза } \\
\text { кластера }\end{array}$ & $\begin{array}{c}\text { Ідентифікатор } \\
\text { суміжного } \\
\text { кластера }\end{array}$ & $\begin{array}{c}\text { Ідентифікатор } \\
\text { шлюза суміжного } \\
\text { кластера }\end{array}$ & $\begin{array}{c}\text { Маршрут до } \\
\text { шлюза суміжного } \\
\text { кластера }\end{array}$ & $\begin{array}{c}\text { Час } \\
\text { актуальності }\end{array}$ \\
\hline bridge & cluster & $\begin{array}{c}\text { bridge_ } \\
\text { cluster }\end{array}$ & $\begin{array}{c}<\text { bridge_ } \\
\text { cluster_route }>\end{array}$ & $<$ tm> \\
\hline$\ldots$ & $\ldots$ & $\ldots$ & $\ldots$ & $\ldots$ \\
\hline
\end{tabular}

Таким чином визначено чітку послідовність передачі даних між вузлами різних кластерів: вузолвідправник - контролер кластера - шлюз кластера - шлюз суміжного кластера - контролер суміжного кластера - вузол-приймач.

Етап реконфігурації мережі. Щоб постійно підтримувати актуальність таблиць маршрутизації та цілісності топології мережі, контролери кластерів періодично (через певні інтервали часу - <tm>) розсилають вузлам інформацію про стани каналів. На це може витрачатися значна частина пропускної здатності, однак значно менше ніж у відомих протоколах проактивної (реактивної) груп. За рахунок того, що всі маршрути відомі і їх треба тільки зчитати зі своєї заздалегідь побудованої таблиці маршрутизації, зменшуються об'єми службового трафіка.

Вводиться нова метрика мережі - мобільність вузлів, що призводить до змін зв'язків між вузлами а отже, існують часті переобрання контролерів кластерів. Важливо оцінювати значення мобільності вузлів і відповідно до нього розробляти протоколи, що адаптуються до частоти оновлень маршруту і хендовера, при цьому кількість транзитних ділянок стає кращою метрикою маршрутизації з врахуванням показників мобільності.

Показники продуктивності мережі залежно від обраної топології мережі.

Вибір топології мережі суттєво може впливати на оптимізацію одного або декількох показників продуктивності. Найчастіше використовують такі показники:

1. Кількість транзитних ділянок. Кількість транзитних ділянок між вузлом-джерелом і вузломадресатом.

2. Очікувана кількість передач - Expected Transmission Counted (ETX) - одна з перших метрик, запропонованих для бездротових мереж, яка враховує кількість спроб, які треба зробити, щоб успішно передати кадр даних. Цей показник характеризує якість радіозв'язку. Таким чином, ії метою $\epsilon$ знаходження шляху з найбільшою ймовірністю доставки пакетів, а не за меншу кількість хопів. Формула, за якою розраховується метрика, має такий вигляд:

$$
\operatorname{ETX}=\frac{1}{d_{f} \cdot d_{r}},
$$

де $d_{f}$ - відсоток успішно доставлених пакетів вузлом у прямому напрямку до суміжного вузла;

$d_{r}$ - відсоток успішно доставлених пакетів у зворотному напрямку.

Маршрут, сумарна метрика якого буде мінімальною, буде визначений як оптимальний для відправки пакетів даних до призначення.

3. Очікуваний час передачі - Expected Transmission Time (ETT). Показник є покращеним ETX, оскільки для його розрахунку використовується пропускна здатність каналу зв'язку. Це особливо актуально, коли використовуються різні мережеві технології (наприклад, IEEE 802.11a і IEEE 802.11b) для вибору напрямку передачі за різними шляхами. Її розрахунок може бути виконаний по-різному. У [13, с. 2730] вона розраховується як розширення метрики ЕTX і має наступний вигляд:

$$
E T T=E T X \cdot \frac{S}{B},
$$

де $E T X$ - метрика, обчислювана за формулою (5);

$S$ - розмір пробного пакета;

$B$ - пропускна здатність ланки.

Для передачі даних аналогічно попередньому випадку обирається маршрут з найменшим сумарним значенням метрики ETT.

Слід зазначити, що окрім цих формул є й інші підходи до розрахунку метрик. Вони менш поширені, основна їх частина не стандартизована та перебуває у якості рекомендацій до того чи іншого протоколу.

4. Енергоспоживання. Енергетичний рівень вузла можна розглянути як метрику маршрутизації, якщо деякі вузли мають обмежений запас живлення їх участь у процесі маршрутизації може призвести до відмови з'єднання з каналом. 
5. Доступність/надійність шляху. Цей показник визначає ймовірність, коли шлях доступний за інтервал часу та дозволяє врахувати мобільність вузла.

У процесі функціонування мобільної мережі здійснюється її реконфігурація з метою зменшення часу на передачу інформації і оптимізації мережевого трафіка. Тому, для критерію вибору структури і розміру кластерів запропоновано розраховувати безрозмірний коефіцієнт ефективності передачі даних, що дорівнює:

$$
K_{I}=\frac{W_{\kappa}}{W_{\kappa}+W_{c л}}
$$

де $W_{\kappa}$ - кількість переданих користувацьких даних; $W_{c л}-$ службовий трафік.

Критерій ефективності динамічної маршрутизації визначається об'ємом службового трафіка, що має бути зведений до мінімуму. Об'єм службового трафіка подається як функція $W_{c л}=f\left(F_{r e c}, V_{0}\right)$ від частоти реконфігурації мережі $F_{r e c}$ і кількості вузлів $n \cdot V_{i}$ у кластері $V_{i}$. Зі збільшенням числа реконфігурацій у мережі об'єм службового трафіка збільшується за нелінійним законом, як наслідок - різко знижується ефективність передачі даних. При визначених умовах це може призвести до нестійкої роботи мережі. Тому, для зменшення службового трафіка необхідно мінімізувати частоту реконфігурацій та кількість кластерів мережі на проміжку часу $\Delta t$.

Приклад. Нехай задано мережу мобільних вузлів $(N=30)$. На першому етапі за геометричним розташуванням територіально-розділені вузли (рис. $1, a$ ) розподілено на кластери (рис. 1, б). Визначено доступність вузлів усіх кластерів, сформовано таблиці маршрутизації кожного вузла.

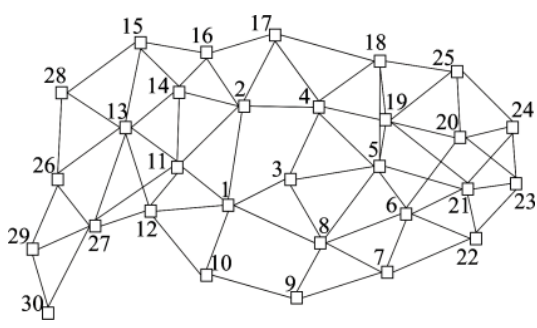

a)

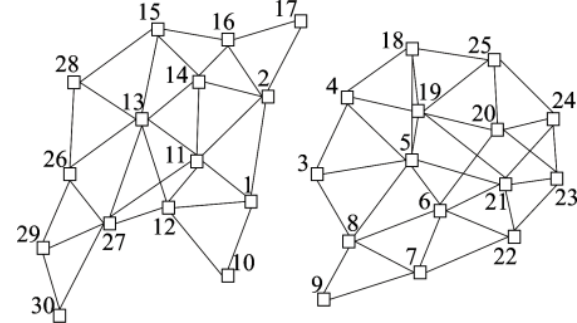

б)

Рис. 1. Перший етап формування мережі:

а) мобільні вузли, з’єднанні за радіусом дї вузла; б) результат кластеризації

Для кластерів № 1, 2 потенційними контролерами кластерів є вузли 3 номерами 13, 5 відповідно. Кожен контролер кластера містить таблицю маршрутизації фізичного (табл. 6) та віртуального доступу до мережі.

Таблиия 6

Приклад таблииі маршрутизаиії контролера кластера мережі (вузол № 13)

\begin{tabular}{|c|c|c|c|c|}
\hline $\begin{array}{c}\text { Ідентифікатор } \\
\text { контролера кластера }\end{array}$ & $\begin{array}{c}\text { Ідентифікатор } \\
\text { вузла }\end{array}$ & Маршрут & Вартість маршруту & $\begin{array}{c}\text { Час } \\
\text { актуальності }\end{array}$ \\
\hline \multirow{3}{*}{13} & 1 & $11-1$ & distance (1) & <ЧЧ:ММ> \\
\cline { 2 - 5 } & 2 & $14-2$ & distance (2) & \\
\cline { 2 - 5 } & \multicolumn{4}{|c|}{$\ldots$} \\
\cline { 2 - 5 } & 30 & $26-29-30$ & distance (30) & \\
\hline
\end{tabular}

Вузлами-шлюзами $є$ вузли $(1,2)$ та $(3,4)$ кластерів 1,2 відповідно. На рисунку 2 зображено віртуальну магістраль. 


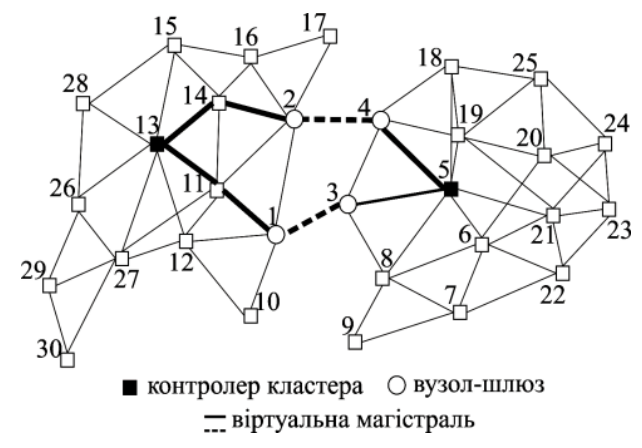

Рис. 2. Кластеризована модель мережі передачі даних

Відповідно до [14, с. 63] розраховано об'єм службової інформації для повнозв'язної мережі передачі даних: $W_{c r}=N^{2}(\operatorname{dev}(i)-1)=900 \cdot 29=26100$, де $\operatorname{dev}(i)-$ степінь $i$-ої вершини, який для повнозв'язної мережі передачі даних буде на одиницю меншим за кількість вершин.

Для мережі передачі даних об’єм службової інформації розраховано за допомогою такого виразу:

$$
W_{c l}=\sum_{i=1}^{N} \operatorname{dev}(i) \cdot(\operatorname{dev}(i)-1) .
$$

За виразом (8) розраховано об'єм службової інформації для: мережі 3 децентралізованим управлінням (рис. $1, a)-W_{\text {деенпр }}=20800$; мережі, розподіленій на кластери (рис. 2$)-W_{\text {касст }}=13936$.

3 метою оцінювання ефективності розподілення мережі передачі даних на кластери застосовано безрозмірний коефіцієнт ефективності кластеризації, який відображає ступінь зменшення об'єму службової інформації:

$$
K_{\kappa л}=\frac{W_{\text {дечентр }}}{W_{\kappa л}} .
$$

Відповідно до виразу (9) при розподіленні мережі передачі даних на кластери об'єм службової інформації знизився в 1,49 раза.

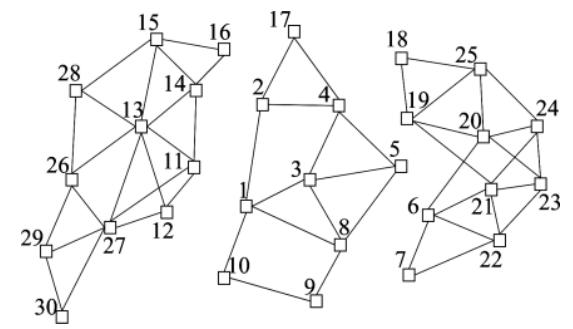

a)

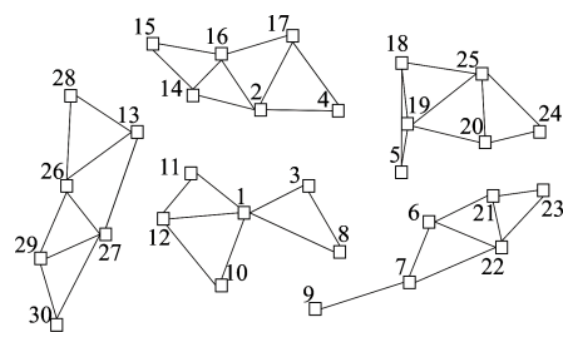

b)

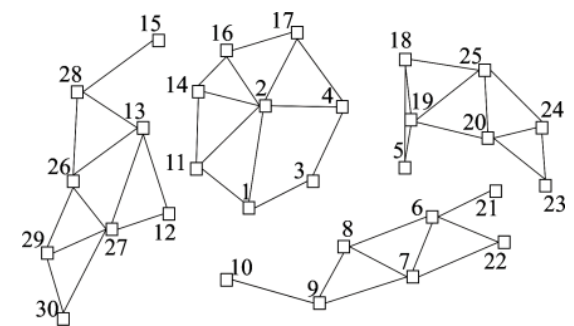

б)

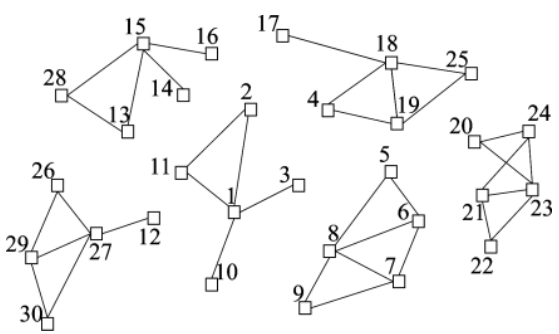

2)

Рис. 3. Результат кластеризаиії: а) 3 кластери; б) 4 кластери; в) 5 кластерів; г) 6 кластерів

Результати розрахунків об’єму службової інформації при ініціалізації та пакетній передачі даних децентралізованою мережею наведено в таблиці 7. 
Значення службової інформачії для кластеризованої мережі

\begin{tabular}{|c|c|c|c|c|}
\hline \multirow{2}{*}{$\begin{array}{c}\text { Кількість } \\
\text { кластерів }\left(k_{\text {кл }}\right)\end{array}$} & \multicolumn{2}{|c|}{$\begin{array}{c}\text { Об’єм службового трафіка } \\
\left(W_{\text {кл_сл }}, \text { байт) при: }\right.\end{array}$} & \multicolumn{2}{|c|}{$\begin{array}{c}\text { Приріст об’єму (рази) порівняно 3 } \\
\text { повнозв’язною мережею }\end{array}$} \\
\cline { 2 - 5 } & $\begin{array}{c}\text { ініціалізації } \\
\text { мережі }\end{array}$ & $\begin{array}{c}\text { передачі } \\
\text { даних }\end{array}$ & $\begin{array}{c}\text { збільшення } \\
\text { при ініціалізації }\end{array}$ & $\begin{array}{c}\text { зменшення } \\
\text { при передачі }\end{array}$ \\
\hline 1 & 14298 & 1248 & 1,06 & 10,8 \\
\hline 2 & 14604 & 1554 & 1,08 & 8,7 \\
\hline 3 & 15088 & 2038 & 1,12 & 6,6 \\
\hline 4 & 15531 & 2481 & 1,15 & 4,6 \\
\hline 5 & 15998 & 2948 & 1,19 & 4,0 \\
\hline 6 & 16443 & 3393 & 1,22 & \\
\hline
\end{tabular}

Висновки та перспективи подальших досліджень. Аналіз отриманих результатів свідчить про те, що застосування методу децентралізованого управління мережевими ресурсами забезпечує зменшення (до 10 разів) обсягу службової інформації при організації передачі даних кластеризованою мережею порівняно із повнозв'язною. При ініціалізації такої мережі службовий трафік такої мережі більший (на 10-12 \%) за рахунок виокремлення службової інформації для визначення структурних елементів мережі (контролерів кластерів, вузлів-шлюзів тощо). Застосування такого підходу синтезу мереж ефективне при забезпеченні інформацією абонентів з високим ступенем оперативності, однак при мінімальній кількості кластерів, на яку розбивається мережа.

У подальшому планується удосконалення методу шляхом оптимізації вибору кількості контролерів та шлюзів з метою забезпечення надійності та оперативності передачі даних бездротовими мережами.

\section{Список використаної літератури:}

1. Астраханщев A.A. Сравнительный анализ эффективности протоколов маршрутизации в AD-HOC сетях / А.А. Астраханцев, С.М. Горбань // Системи обробки інформації. - 2014. - № 1 (117). - С. 156-159.

2. Traffic engineering in software-defined networking: Measurement and management / Zhaogang Shu, Jiafu Wan, Jiaxiang Lin and other // Access IEEE. - 2016. - Vol. 4. - P. 3246-3256.

3. Метод диференційованого мультипотокового керування трафіком у транспортних програмно-керованих мережах / M.М. Климаи, О.М. Шиур, В.О. Багрій, А.Л. Швець // Вісник Національного університету «Львівська політехніка». Радіоелектроніка та телекомунікації. - 2014. - № 796. - С. 60-68.

4. Kuchuk G.A. Method of synthesis of the information structure of the coherent fragment of the corporate multiservice network / G.A. Kuchuk // Collection of scientific works of the Kharkiv University of Air Forces. 2013. - No. 2 (35). - P. 97-102.

5. Корещький О.В. Моделі та алгоритми підвищення ефективності комутації інформаційних потоків у повністю оптичних телекомунікаційних системах / O.В. Кореиький, С.С. Думич // Вісник Національного університету «Львівська політехніка». Радіоелектроніка та телекомунікації. - 2013. - № 766. - С. 96-103.

6. Колесник А.Б. Оценка эффективности алгоритмов оптимизации загрузки и маршрутизации в беспроводных сетях / А.Б. Колесник // Вестник Херсонского государственного технического университета. - 2006. № 1 (24). - C. 549-553.

7. Boukerche A. Algorithms and protocols for wireless, mobile ad hoc networks / A.Boukerche // New Jersey : John Wiley \& Sons, Inc., 2009. - 495 p.

8. Краснобаев В.А. Протоколы маршрутизации в беспроводных сенсорных сетях / В.А. Краснобаев, P.A. Горбенко // Системи управління, навігації та зв'язку. - 2013. - Вип. 2 (26). - С. 114-120.

9. Draves R. Comparison of Routing Metrics for Static Multi-hop Wireless Networks / R.Draves, J.Padhye, B.Zill // Proceedings of the 2004 Conference on Applications, Technologies, Architectures, and Protocols for Computer Communications. - New York, USA, 2004. - P. 133-144.

10. Шатовская Т.Б. Анализ данных сложных объектов с помощью модифицированного алгоритма кластеризации / Т.Б. Шатовская, О.О. Дорожко // Восточно-Европейский журнал передовых технологий. 2014. - № 2/4 (68). - C. 155-159.

11. Kriegel H.-P. Clustering high-dimensional data: A survey on subspace clustering, pattern-based clustering, and correlation clustering / H.-P. Kriegel, P.Kr oger, A.Zimek // ACM Transactions on Knowledge Discovery from Data (TKDD). - 2009. - № 3 (1). - P. 1-58.

12. Воробиенко П.П. Принципы организации сетей с коммутацией пакетов : учебное пособие / П.П. Воробиенко, О.Л. Нечипорук, М.И. Струкало. - Одесса : УГАС им. А.С. Попова, 2000. - 101 с.

13. Saad Biaz iETT: A Quality Routing Metric for Multi-rate Multi-hop Networks / Saad Biaz, Bing Qi [Електронний pecypc]. - Режим доступу : http://www.eng.auburn.edu/users/sbiaz/publications/IETT-Bing2008.pdf.

14. Boychenko O. Multicriterion Estimation of Efficiency of Mobile Network Clustering / O.Boychenko, V.Vorotnikov, Y.Kulakov // The Advanced Science Journal. - 2015. - Issue 1. - P. 61-67. 


\section{References:}

1. Astrakhantsev, A.A. and Horban', S.M. (2014), «Sravnitel'nyi analiz effektivnosti protokolov marshrutizatsii v ADHOC setyakh», Systemy obrobky informatsiyi, No. 1 (117), pp. 156-159.

2. Zhaogang, Shu, Jiafu, Wan and Jiaxiang, Lin (2016), «Traffic engineering in software-defined networking: Measurement and management», Access IEEE, Vol. 4, pp. 3246-3256.

3. Klymash, M.M., Shpur, O.M., Bahriy, V.O. and Shvets,' A.L. (2014), "Metod dyferentsiyovanoho mul'typotokovoho keruvannya trafikom u transportnykh prohramno-kerovanykh merezhakh», Visnyk Natsional'noho universytetu «L'vivs'ka politekhnika». Radioelektronika ta telekomunikatsiyi, No. 796, pp. 60-68.

4. Kuchuk, G.A. (2013), «Method of synthesis of the information structure of the coherent fragment of the corporate multiservice network», Collection of scientific works of the Kharkiv University of Air Forces, No. 2 (35), pp. 97-102.

5. Korets'kyy, O.V. and Dumych, S.S. (2013), «Modeli ta alhorytmy pidvyshchennya efektyvnosti komutatsiyi informatsiynykh potokiv u povnistyu optychnykh telekomunikatsiynykh systemakh», Visnyk Natsional'noho universytetu «L'vivs'ka politekhnika». Radioelektronika ta telekomunikatsiyi, No. 766, pp. 96-103.

6. Kolesnik, A.B. (2006), «Otsenka effektivnosti algoritmov optimizatsii zagruzki i marshrutizatsii v besprovodnykh setyakh», Vestnik Khersonskogo gosudarstvennogo tekhnicheskogo universiteta, No. 1 (24), pp. 549-553.

7. Boukerche, A. (2009), «Algorithms and protocols for wireless, mobile ad hoc networks», John Wiley \& Sons, Inc., New Jersey, 495 p.

8. Krasnobaev, V.A. and Horbenko, R.A. (2013), «Protokoly marshrutyzatsyy v besprovodnykh sensornykh setyakh», Systemy upravlinnya, navihatsiyi ta zv'yazku, Vyp. 2 (26), pp. 114-120.

9. Draves, R., Padhye, J. and Zill, B. (2004), «Comparison of Routing Metrics for Static Multi-hop Wireless Networks», Proceedings of the 2004 Conference on Applications, Technologies, Architectures, and Protocols for Computer Communications, New York, USA, pp. 133-144.

10. Shatovskaya, T.B. and Dorozhko, O.O. (2014), «Analiz dannykh slozhnykh ob"yektov s pomoshch'yu modifitsirovannogo algoritma klasterizatsii», Vostochno-Yevropeyskiy zhurnal peredovykh tekhnologiy, No. 2/4 (68), pp. 155-159.

11. Kriegel, H.-P., Kr"oger, P. and Zimek, A. (2009), «Clustering high-dimensional data: A survey on subspace clustering, pattern-based clustering, and correlation clustering», ACM Transactions on Knowledge Discovery from Data (TKDD), No. 3 (1), pp. 1-58.

12. Vorobiyenko, P.P., Nechiporuk, O.L. and Strukalo, M.I. (2000), «Printsipy organizatsii setey s kommutatsiyey paketov», uchebnoye posobiye, UGAS im. A.S. Popova, Odessa, $101 \mathrm{p}$.

13. Saad, Biaz and Bing, Qi, iETT: A Quality Routing Metric for Multi-rate Multi-hop Networks, [Online], available at: http://www.eng.auburn.edu/users/sbiaz/publications/IETT-Bing2008.pdf

14. Boychenko, O., Vorotnikov, V. and Kulakov, Y. (2015), «Multicriterion Estimation of Efficiency of Mobile Network Clustering», The Advanced Science Journal, Issue 1, pp. 61-67.

Пількевич Ігор Анатолійович - доктор технічних наук, професор, професор кафедри комп'ютерної інженерії та кібербезпеки Державного університету «Житомирська політехніка».

ORCID: http:// orcid.org/ 0000-0001-5064-3272

E-mail: igor.pilkevich@meta.ua.

Бойченко Олег Сергійович - кандидат технічних наук, начальник науково-дослідної лабораторії наукового центру Житомирського військового інституту імені С.П. Корольова.

ORCID: http:// orcid.org/ 0000-0003-3048-4184

E-mail: bos_2006@ukr.net.

Гуменюк Ігор Володимирович - кандидат технічних наук, старший викладач кафедри захисту інформації та кібербезпеки Житомирського військового інституту імені С.П. Корольова.

ORCID: http:// orcid.org/ 0000-0001-5853-3238

E-mail: ig_gum@ukr.net. 